\title{
The Future of Cardiac Safety Studies
}

\section{Pandya PA*}

Reliance Life Sciences, Mumbai, India

\section{Introduction}

Across the last several decades, to establish cardiac safety has been a major concern during drug development process. It was found that, many drugs are associated with sudden death and causing fatal arrhythmia. It is difficult identify compound having cardiac toxicity. However, one common effect of these drugs was to prolong QT but the challenge is to find whether this problem is related to parent drug or metabolite or due to drug interaction or combination of all three?

\section{Thorough QT/QT Study}

The objective of "thorough QT/QT study" on health human population is to identify whether drug has a threshold pharmacologic effect on cardiac repolarization as it is regulatory concern $[1,2]$. This is generally detected by QT/QT prolongation. Such studies are planned during early phase of drug development which help to provide maximum guidance for the later studies (Figure 1) [3,4].

\section{There are Several Limitations of Thorough $Q t / Q t$ Studies}

1. QT is not considered to be strong biomarker as there are no consensus on the best suited method of acquiring, measuring, and analysing the QT interval during studies as due to poor signal, low frequency, low amplitude and has poor signal-to-noise ratio affected by several confounding factors. In addition, there is poor link between the experimental model of $\mathrm{QT}_{\mathrm{c}}$ and clinical events. Many times, it's difficult to establish link between different episodes reported during study [1,5-7].

2. Prolongation of QT internal is also linked with many other factors. It's not always a risk. Marketing approval with "Warning label" was considered for several drugs [8].

3. It's very expensive to conduct "thorough QT/QT studies" $[9,10]$.

\section{Conclusion}

The most common reason for the drug withdrawal includes QT prolongation and pro-arrhythmias. To prove cardiac safety become extremely difficult for the developers once compound is shown prolong QT during drug development [11].

Refinement in regulations is needed based on earlier experience along with careful planning during pre-clinical stage to review Multiple Iron Channels (MICE), isolated cardiac myocytes, multiple Electrocardiography (ECG) collection, use of computer modelling and

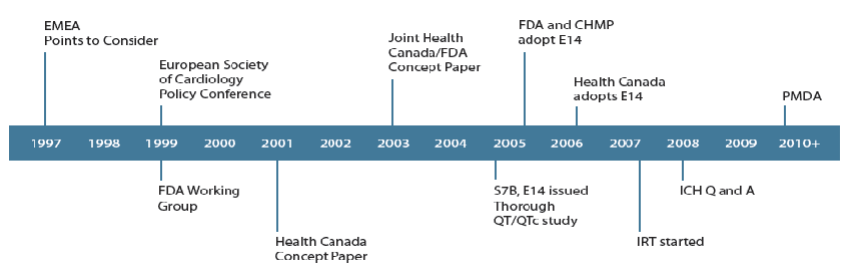

Figure 1: The regulatory evolution of the TQT study [4]. placing a premium on ER relationships [12-14]. The best strategy is to keep ECG as vital data point and establish cardiac safety with the help from preclinical information and early phase human studies keeping several other cardiac biomarkers (heart rate, lipids, CRP, BP, BNP, troponin and imaging) in consideration.

\section{References}

1. Shah RR (2002) Drug-induced prolongation of the QT interval: why the regulatory concern? Fundam Clin Pharmacol 16: 119-124.

2. Callahan T (2014) The Future of QT in Clinical Trials. Appl Clin Trials 20143.

3. Darpo B (2010) The thorough QT/QT study 4 years after the implementation of the ICH E14 guidance. Br J Pharmacol 159: 49-57.

4. Wheeler W (2010) Evolution of the Thorough QT/QT study. Clin Trials-TQT Stud 7: 21-23.

5. Azie NE, Adams G, Darpo B, Francom SF, Polasek EC, et al. (2004) Comparing methods of measurement for detecting drug-induced changes in the QT interval: implications for thoroughly conducted ECG studies. Ann Noninvasive Electrocardiol 9: 166-174.

6. Accelerating the Development of Biomarkers for Drug Safety (2009) Institute of Medicine (US) Forum on Drug Discovery, Development, and Translation. Washington (DC): National Academies Press, USA.

7. Badilini F, Maison-Blanche $P(2005)$ Holter monitoring for QT: the RR bin method in depth. In: Morganroth J, Gussak I (eds.) Cardiac Safety of Noncardiac Drugs: Practical Guidelines for Clinical Research and Drug Development, Humana Press Inc, Totowa, NJ, USA pp: 167-185.

8. Barbey JT, Lazzara R, Zipes DP (2002) Spontaneous adverse event reports of serious ventricular arrhythmias, QT prolongation, syncope, and sudden death in patients treated with cisapride. J Cardiovasc Pharmacol Ther 7: 65-76.

9. Dixon R, Job S, Oliver R, Tompson D, Wright JG, et al. (2008) Lamotrigine does not prolong QT in a thorough QT/QT study in healthy subjects. Br J Clin Pharmacol 66: 396-404.

10. http://www.ich.org/fileadmin/Public_Web_Site/ICH_Products/Guidelines/ Efficacy/E14/E14_Guideline.pdf

11. Garnett CE, Beasley N, Bhattaram VA, Jadhav PR, Madabushi R, et al. (2008) Concentration-QT relationships play a key role in the evaluation of proarrhythmic risk during regulatory review. J Clin Pharmacol 48: 13-18

12. Turner JR, Kothari S, Cabell CH (2013) Fifteen years of cardiac safety: history, state-of-the-science research, and glimpses into the future. Int Pharmaceut Ind 5: 98-104.

13. Strnadova C (2005) The assessment of $Q T / Q T_{c}$ interval prolongation in clinical trials: A regulatory perspective. Drug Inf J 39: 407-433.

14. Shah RR (2002) Drug-induced prolongation of the QT interval: regulatory dilemmas and implications for approval and labelling of a new chemical entity. Fund Clin Pharmacol 16: 147-156.

*Corresponding author: Pandya PA, Program Management, Reliance Life Sciences, Mumbai, India, Tel: +91-9967017172; E-mail: drpandya18@gmail.com

Received March 28, 2017; Accepted March 29, 2017; Published April 07, 2017

Citation: Pandya PA (2017) The Future of Cardiac Safety Studies. J Bioequiv Availab 9: e78. doi:10.4172/jbb.10000e78

Copyright: ( 2017 Pandya PA. This is an open-access article distributed unde the terms of the Creative Commons Attribution License, which permits unrestricted use, distribution, and reproduction in any medium, provided the original author and source are credited. 